\title{
Consent to treatment
}

\author{
Seeking a person's consent to treatment is, not only a legal obligation, \\ but also enmeshed with respecting the person's autonomy and \\ dignity for self-determination. This article discusses the evolving concept \\ of consent among patients requiring wound care.
}

Keywords:

consent; valid; informed; voluntary; capacity; human rights

\section{ABSTRACT \\ Background}

Patients' valid consent to treatment must be gathered prior to providing treatment to ensure the protection of a person's rights. This article discusses the key components of a valid consent to treatment, as well as different forms of consent. Two case scenarios also consider pertinent consent issues related to wound care provision. Using a human-rights-based approach $^{1}$, the Fairness, Respect, Equality, Dignity and Autonomy (FREDA) principles ${ }^{2}$, linked to the Convention of the Rights of People with Disabilities $(2006)^{3}$, provide a useful guiding framework and resource for clinical decision-making.

\section{Key messages}

1. Gaining valid consent to treatment and respecting a person's right to self-determination.

2. Ensuring consent is not devalued by the routinised provision of care procedures.

3. The value of consent is more than gaining permission to carry out a procedure. It is a process that respects a person's autonomy and rights. This process is person-centred and includes service users as active participants in their own health care decision-making
Is gaining consent a tick box exercise? Seeking a person's consent to treatment is, not only a legal obligation, but also enmeshed with respecting the person's autonomy and dignity for self-determination. On the $72^{\text {nd }}$ anniversary of the United Nations Universal Declaration of Human Rights (UDHR) $(1948)^{4}$, it is useful to consider the basic ethical and legal principle of 'consent to treatment' and its implications for clinical practice. Associated with both civil and criminal law, consent is acknowledged by the United Nations Committee on Economic, Social and Cultural Rights (CESCR) 5 as a core concept, obliging states to support 'people to make informed choices about their health'. ${ }^{1}$ Using case scenarios, this article discusses the evolving concept of consent among patients requiring wound care. This population may be considered vulnerable due to comorbidities, such as frailty and advanced age. Additionally, the procedure of gaining patient consent could be devalued or nullified because of the frequency or routinised provision of wound care. ${ }^{6}$ Therefore, gaining consent for a wound care procedure could become a perfunctory, bureaucratic matter, conducted as a 'tick box' exercise.

The Fairness, Respect, Equality, Dignity and Autonomy (FREDA) principles ${ }^{1}$ provide a humanrights-based approach and guiding framework for clinical care. These principles are linked to human rights legislation, including the European Union's 
Charter of Fundamental Rights (CFR) $(2000)^{7}$ and the United Nation's Convention on the Rights of Persons with Disabilities (UN CRPD) (2006). ${ }^{3}$ In the case scenarios it examines, this research will use the FREDA principles to provide a useful aid and resource for considering whether elements of consent are met. ${ }^{2}$ There are three key elements to valid consent to treatment. Consent must be voluntary; it must be informed; and the person giving consent must have the mental capacity to do so. ${ }^{8}$

\section{Consent must be voluntary}

People must give their consent of their own free will, without duress, coercion or undue influence. Consent is specific to the particular procedure being planned, and any information given by the clinician relates to that procedure. ${ }^{8}$

The Right to Refuse Treatment: If people voluntarily give consent, they also have the right to voluntarily refuse to consent, withdraw their consent and change their minds. Refusing treatment may appear unusual, or even peculiar, to others, and, in some cases, it may lead to death. However, if the three components of a valid consent have been met, people reserve the right to make their own decisions regarding treatment.

\section{Consent must be informed}

To give a valid consent, people must have the pertinent information to make informed decisions. When sufficient information is provided in an accessible, unbiased manner, clinicians have discharged their duties to disclose. However, difficulties can arise when clinicians are unsure of what is appropriate, pertinent information. Insufficient information provided in an inaccessible manner could be considered negligence and a failure of the clinicians to discharge their duties. ${ }^{9}$ In some extreme situations, this could give rise to a claim for battery. In recent years, the legal principle has evolved into the 'reasonably prudent patient or patient-centred test. ${ }^{\text {II }}$ This test is based on what a patient considers to be relevant, pertinent information, not merely on the information the clinician provides. However, an exception to this is 'therapeutic privilege'. III In these circumstances, the clinician may not disclose information to a patient if it is believed that serious psychological harm would be incurred by that disclosure.

In a claim for negligence or battery, the people making the claim (plaintiffs) must prove that the information provided to them was insufficient or irrelevant and that the warnings given were inadequate, thereby damaging them.

\section{Forms of consent}

Consent may be given in many forms, including orally or in writing. It can also be implied or explicit. Both oral and written methods are valid for gaining consent. However, it may not always be straightforward to prove that oral consent was given. With written consent, there is a record of consent being gained. ${ }^{8}$

Implied Consent: If people visit a clinician, it could be implied that, in so doing, they consent to the clinician's examination. ${ }^{8}$

Necessary consent: In urgent circumstances, where it may be impossible to gain consent prior to giving treatment, the courts will accept that, due to the urgent necessity of treatment, consent was implied.

Express consent: In this situation, people have expressed their consent to treatment in writing. This consent is clear, transparent and unambiguous. However, the consent given is explicit and limited to a particular treatment or intervention, and, if the three key elements of consent are not met, the consent is invalid. Express consent must be voluntary and informed, and the people must have the capacity to give their consent. ${ }^{8}$

Withdrawal of consent: Having once given consent, a person reserves the right to withdraw that consent at any stage of an intervention or procedure. ${ }^{8}$

\section{Decision-making capacity}

Adults are presumed to have mental capacity, unless proven otherwise, and legal capacity is the legal recognition of people's choices and their capacities to exercise their rights. In situations when an adult person's mental capacity is compromised, the courts will make decisions on his or her behalf if no one else has been given power of attorney. In recent years, many jurisdictions have moved to support and assist those with impaired mental decision-making capacities. This person-centred approach focuses on the will, preferences, wishes and perspectives of a person. This type of decision-making is supported in various modes, including: assisted decision-making, co-decision-making and the application of courtappointed decision-makers. ${ }^{9}$ Issues such as whether a situation is temporary or permanent, as well as pos- 


\section{Is consent voluntary and informed, and is the person giving consent recognised as a person under the law?}

An 86-year-old person living alone at home has a lower leg wound for three months, requiring weekly dressings. The wound dressing procedure is painful, lengthy and tiring. The patient has refused to consent to the wound being dressed for two consecutive weeks. The community nurse has discussed the situation with the patient and has explained there is a risk of further infection. The nurse's assessment is that the patient understands the information, appreciates its significance and can retain it. The nurse also knows that she cannot apply undue influence or duress to the patient but is very concerned about the patient's health and safety.

Using the FREDA principles linked to the $2006 \mathrm{UN} \mathrm{CRPD}^{2}$, the clinician should consider the following possible steps.

- Fairness and Respect: Review the mode of communication. Could the information be provided to the patient in multiple modes to ensure full understanding? (This is linked to UN CRPD Article 21: 'Freedom of Expression and Opinion, and Access to Information').

- Equality: Review the time and place of giving the information. If the person is normally visited in the afternoon, could this be changed to a morning visit? (This is linked to Article 23: 'Respect for Home and the Family').

- Dignity: Review the personnel at the meeting with the patient. Consider involving other persons, whom the patient might consider helpful. (This is linked to UN CRPD Article 17: 'Protecting the Integrity of the Person' and Article 22: 'Respect for Privacy).

- Autonomy: Review analgesia options, timing of procedure, wound dressing options and the personnel performing the procedure. ${ }^{11}$ (This is linked to UN CRPD Article 14: 'Liberty and Security of the Person' and Article 19: 'Living Independently and being Included in the Community').

sible treatment options, are considered. All adults, and, in particular, older people and those who know that their mental capacity is failing, are encouraged to formally make their will and preferences known so they will be observed and legally recognised should the need arise. In a paradigm shift, Bronan and Flynn $(2017)^{10}$ believe that the determinants of consent should be reviewed to reduce discrimination against certain parties.

Consent, however, still must be evaluated to ensure the person's views are clearly expressed and communicated and the proposed course of action clearly agreed. The concept of consent continues to evolve.
As such, the FREDA principles and current legislation provide guiding frameworks to enable healthcare providers to consider their critical thinking, clinical reasoning and clinical judgement. Two case scenarios use the FREDA principles to provide human-rightsbased, decision-making aid.

This short article highlights the significance of protecting a person's self-determination and autonomy when gaining valid, informed consent. Obtaining informed consent for clinical procedures, such as wound dressing, is both an ethical and a legal requirement. When correctly conducted, the consent process enables patients to make informed and voluntary decisions about accepting or declining clinical care. 


\section{REFERENCES}

1. Council of Europe, European Convention for the Protection of Human Rights and Fundamental Freedoms as amended by Protocols Nos. 11 and 14, 4 November 1950, ETS 5.available at : https://www. refworld.org/doicid/3ae6b3b04.html (accessed 12 March 2020)

2. Curtice M, Exworthy T. FREDA: a human rights-based approach to healthcare. The Psychiatrist. 2010;34:150-6.

3. UN General Assembly [Cited 14 Feb. 2020]. Convention on the Rights of Persons with Disabilities. 13 Dec. 2006. A/RES/61/106, Annex I. Available from: https://www.refworld.org/docid/4680cd212.html

4. UN General Assembly [Cited 14 Feb. 2020]. Universal declaration of human rights. 10 Dec. 1948. 217 A

(III). Available from: https://www.refworld.org/docid/ 3ae6b3712c.html [accessed 14 February 2020].
5. UN Committee on Economic, Social and Cultural Rights (CESCR) [Cited 14 Feb. 2020]. General comment no. 14: the right to the highest attainable standard of health (Art. 12 of the Covenant). 11 Aug. 2000. E/C.12/2000/4. Available from: https://www. refworld.org/docid/4538838d0.html

6. Ploug T, Holm S. Informed consent and routinisation J Med Ethics 2013;39:214-8.

7. European Union [Cited 14 Feb. 2020]. Charter of fundamental rights of the European Union. 2012 Oct. 26. 2012/C 326/02. Available from: https:// www.refworld.org/docid/3ae6b3b70.html

8. Mills S, Mulligan A. Medical law in Ireland 3rd ed. London: Bloomsbury; 2017.
9. S.I. No. 517/2016 - Assisted decision-making (capacity) Act 2015 (commencement of certain provisions) (no. 2) order 2016 [Cited 14 Feb. 2020]. Available from: http://www.irishstatutebook.ie/eli/2016/si/517/made/ en/print

10. Brosnan L, Flynn E. Freedom to negotiate: a proposal extricating 'capacity' from 'consent'. Int J Law Context 2017;13(1):58-76

11. Royal College of Nursing. Principles of consent: guidance for nursing staff, London: RCN;2017. Health information and quality authority guidance on a human rights-based approach in health and social care services. Dublin: HIQA; 2019.

\section{Cases}

I. UN CESCR 2000 37(3) (iv).

II. Rogers v Whitaker [1992] HCA 58.; Montgomery v Lanarkshire Health Board [2015] UKSC11.

III. Montgomery v Lanarkshire Health Board [2015] UKSC.

\section{Useful Resources}

In Ireland, the National Consent Policy (Health Service Executive 2013) provides guidance about giving information to patients before consent to procedures. The General Medical Council (2008) and the Royal College of Nursing 10 also provide detailed information on informed consent.

UN CRPD Article 3 - 'The principles of the present Convention shall be:

(a) Respect for inherent dignity and individual autonomy, including the freedom to make one's own choices and the independence of persons.

(b) Non-discrimination. (c) Full and effective participation and inclusion in society

(d) Respect for differences and acceptance of persons with disabilities as part

of human diversity and humanity.

(e) Equality of opportunity.

(f) Accessibility.

(g) Equality between men and women.

(h) Respect for the evolving capacities of children with disabilities and respect for the rights of children with disabilities to preserve their identities.' 